\title{
Remembrance of Images Past
}

\author{
By Jan Uhde
}

Fall 2009 Issue of KINEMA

In 2007, BBC broadcast a ten-part TV series based on the legendary archive of the French industrialist and philanthropist Albert Kahn who, at the beginning of the twentieth century, dispatched photographers and cameramen all over the world to gather material for his visionary archive of the planet. Between 1909 and 1929, more than 72,000 colour photographs and over 180,000 metres of film were collected, recorded in large part on the astonishing Autochrome Lumière, the world's first true colour process.

After two years of prolonged negotiations, the exquisite nine-hour long BBC series has finally been given the world-wide release as a three-disc DVD collection. Truly not to be missed.

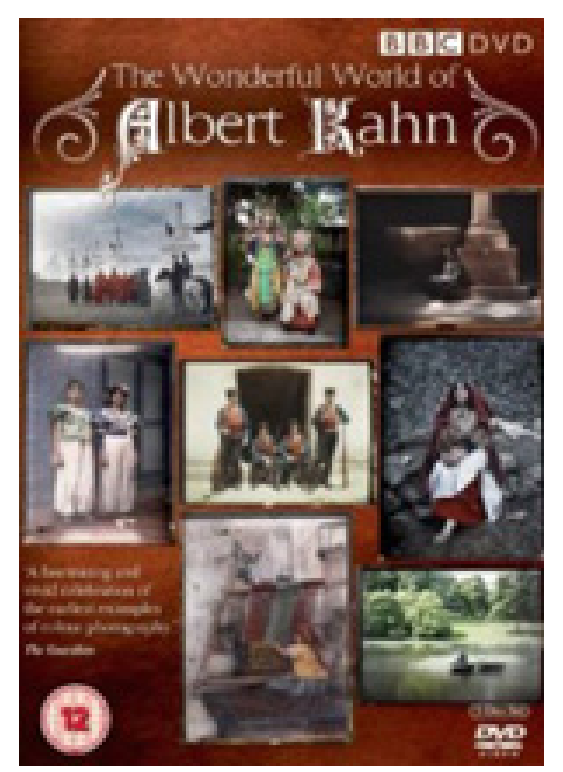

Figure 1: THE WONDERFUL WORLD OF ALBERT KAHN DVD 9 (3-disc set), UK 2009, PAL Regions 2 and 4, 512 min. Booklet. ๆ BBC DVD, Indus Films 2009. GBP 17.98.

The Thirties in Colour, although not a part of the Kahn archive, may nevertheless be seen as its companion piece. Like the Kahn collection, it is based on a successful BBC television documentary mining largely unpublished historical colour archive material, which will doubtlessly help satisfy the growing and quite legitimate demand of contemporary audiences to discover a visual record of the past century.

\section{Author Information}

Jan UHDE is Professor Emer. (Film Studies) at the University of Waterloo, Ontario, Canada. Born in Brno, Czech Republic. Graduated (MA) from the Faculty of Arts, Masaryk University, Brno; PhD received at the University of Waterloo, Ontario, Canada. He taught at the University of Waterloo (1970-2012) where he founded a General and Honours BA program in Film Studies at the Department of Fine Arts.

Publications: Latent Images: Film in Singapore Second edition, with Yvonne Ng Uhde (Ridge Books, National University Press of Singapore, 2010); Latent Images: Film in Singapore, with Yvonne Ng Uhde (Oxford University Press, 2000); Latent Images: Film in Singapore CD-ROM (2003, co-author); Vision and Persistence: Twenty Years of the Ontario Film Institute (University of Waterloo Press, 1990) and Ontario Film 


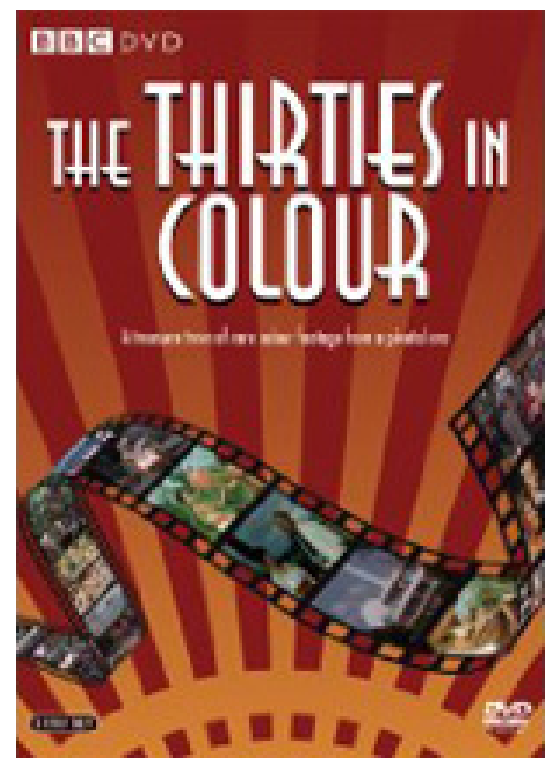

Figure 2: THE THIRTIES IN COLOUR DVD (2-disc set) PAL R-2, 200min BBC-DVD 2009. GBP 10.99 .

Institute Programming Activities Index 1969-1989 (Toronto: Ontario Science Centre, 1990). He co-edited the Place in Space: Human Culture in Landscape (Proceedings from the Second International Conference of the Working Group "Culture and Landscape" of the International Association of Landscape Ecology, Pudoc Scientific Publishers, Wageningen, Holland, 1993). Jan Uhde has published articles and reviews in several countries (including Canada, USA, Germany, Italy), participated in international juries at film festivals and presented papers at international conferences in North America and Europe. In 1998/99, he was a visiting researcher at the School for Film and Media Studies, Ngee Ann Polytechnic, Singapore.

His professional and research interests focus on Singapore cinema; the identification and distancing mechanisms of the film viewer; the non-authored modifications and manipulation of films; and specific aspects of film history, including the Central European cinema.

He founded KINEMA in 1993. 